\title{
Synthesis, Spectral Characterization, and Thermochemical Studies of Poly(phenyl methacrylate peroxide)
}

\author{
Priyadarsi De, ${ }^{1}$ D. N. Sathyanarayana, ${ }^{1}$ P. Sadasivamurthy, ${ }^{2}$ S. Sridhar ${ }^{2}$ \\ ${ }^{1}$ Department of Inorganic and Physical Chemistry, Indian Institute of Science, Bangalore 560012, India \\ ${ }^{2}$ Polymer Laboratory, Insulation Division, Central Power Research Institute, Bangalore 560080, India
}

\section{INTRODUCTION}

Radical polymerization in the presence of oxygen known as oxidative polymerization results in the formation of lowmolecular-weight products with oxygen-containing functional groups (aldehydes, ketones, etc.) in addition to copolymers with oxygen. ${ }^{1}$ The features of the simultaneous occurrence of polymerization and oxidation have been the subject of numerous investigations, and it has led to the establishment of oxidative polymerization as an independent field of radical-chain polymerization.

Since the first report on polyperoxide by Staudinger ${ }^{2}$ in 1925 only a small number of polymers belonging to this class have been characterized. ${ }^{3-6}$ Of these polymers, poly(styrene peroxide) (PSP), first reported by Bovey and Kolthoff, ${ }^{7}$ has received considerable attention. ${ }^{8-16}$ Polyperoxides find applications as polymeric initiators, ${ }^{16-18}$ in preference to conventional simple peroxides, to obtain homopolymers, block copolymers, and novel comb polymers and as curators in coating and molding. ${ }^{19}$ Recently, PSP has been shown to behave as an unique autocombustible polymer fuel, its combustion being controlled by degradation. ${ }^{15}$ The property of autopyrolysis by these polymers is a result of their unusual and highly exothermic heats of degradation.

Early work before the 1960s dealt with the mechanism and kinetics of the oxidative polymerization of vinyl monomers. ${ }^{3-6}$ The spectral characterization of polyperoxides was initiated by Cais and Bovey ${ }^{20}$ in 1977 . However, only a few polyperoxides have been spectroscopically characterized so far. ${ }^{21}$ Interestingly, poly(phenyl methacrylate peroxide) (PP$\mathrm{MAP}$ ), another member of this class of polymers, reported by Razuvaev et al., ${ }^{22}$ has not been characterized by spectroscopic methods. As an autocombustible polymer fuel, it is also of particular interest for studying the degradation behavior of polymeric peroxides. Hence, in the report on the present investigation, spectroscopic studies of the alternating copolymeric structure of PPMAP are discussed. Further, thermal degradation has been studied in detail. The study of

Correspondence to: D. N. Sathyanarayana (dns@ipc.iisc. ernet.in). the mechanism of primary exothermic degradation was supplemented by thermochemical calculations.

\section{EXPERIMENTAL}

\section{Materials}

Phenyl methacrylate (PMA; Lancaster, England) was freed from inhibitor by washing it with $5 \% \mathrm{NaOH}$ and then with water several times. After drying over anhydrous $\mathrm{Na}_{2} \mathrm{SO}_{4}$, it was distilled under reduced pressure. 2,2'-Azobis(isobutyronitrile) (AIBN; Koch-Light, England) was recrystallized twice from methanol. The oxygen used was of high purity. The solvents were purified by standard procedures.

\section{Measurements}

The FTIR spectrum was recorded on a Bruker Equinox 55 FTIR spectrometer. The polymer was taken as thin film cast from $\mathrm{CHCl}_{3}$ solution on the $\mathrm{KBr}$ plates and the spectrum was recorded at room temperature. The $200-\mathrm{MHz}{ }^{1} \mathrm{H}-\mathrm{NMR}$ spectrum was recorded on a Bruker AC-F 200 FT NMR spectrometer in $\mathrm{CDCl}_{3}$. Chemical shifts were assigned with reference to tetramethylsilane (TMS). The ${ }^{13} \mathrm{C}-\mathrm{NMR}$ spectrum $(50.12 \mathrm{MHz})$ was recorded in the same spectrometer using $\mathrm{CH}_{2} \mathrm{Cl}_{2}$ as solvent $\left(\mathrm{D}_{2} \mathrm{O}\right.$ external lock). The molecular weight of the polyperoxide was obtained using a Waters ALC/GPC 224 instrument with THF as a mobile phase at $30^{\circ} \mathrm{C}$, using polystyrene as standard.

Thermal analysis was made using a Perkin-Elmer DSC-2C differential scanning calorimeter (DSC) under nitrogen atmosphere at heating rates of $5^{\circ} \mathrm{C}, 10^{\circ} \mathrm{C}, 20^{\circ} \mathrm{C}, 40^{\circ} \mathrm{C}$, and $80^{\circ} \mathrm{C} / \mathrm{min}$ with a sample size of $1-5 \mathrm{mg}$. Thermogravimetric analysis (TGA) was accomplished on a Mettler Toledo TGA 850 instrument under a nitrogen atmosphere at a heating rate of $10^{\circ} \mathrm{C} / \mathrm{min}$ with a sample weight of $11.2 \mathrm{mg}$.

\section{Computational methods}

The well-documented commercial software packages Insight $\mathrm{II}^{\oplus}$ and the semiempirical program package Ampac/ Mopac (version 6.0) from Biosym Technologies, ${ }^{23}$ were used for the calculation of heats of formation $\left(\Delta H_{f}^{0}\right)$. The Insight II $^{\circledast}$ code assigns an empirical potential energy function to each atom from the central valence force field (cvff) depend- 


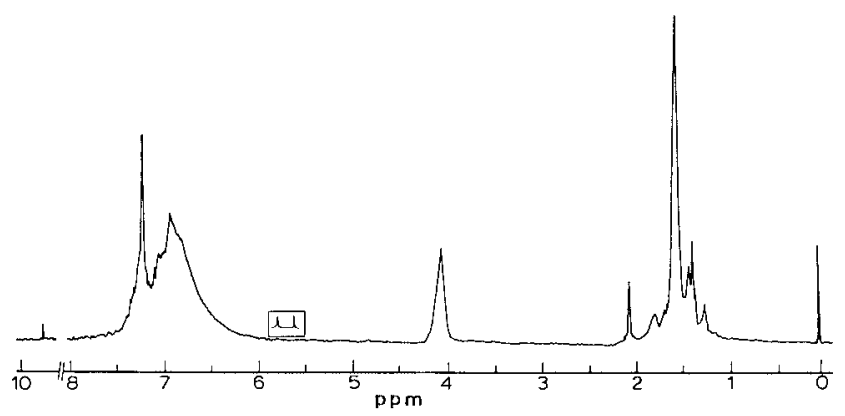

Figure $1{ }^{1} \mathrm{H}-\mathrm{NMR}$ spectrum of PPMAP in $\mathrm{CDCl}_{3}$ (inset: peak at $5.86 \mathrm{ppm}$ are expanded 10 times).

ing on the element type and the nature of the chemical bond. Further, this code has been benchmarked for numerous other molecular systems and its accuracy documented in the literature. The geometry of all the compounds was fully optimized using AM1 Hamiltonian. ${ }^{24,25}$

\section{Polymerization}

PMA was oxidatively polymerized by charging a solution of $2.78 \times 10^{-3} \mathrm{~mol} / \mathrm{L}$ PMA and AIBN $(0.02 \mathrm{~mol} / \mathrm{L})$ in benzene in a Parr reactor equipped with stirrer (Parr Instrument Co., Moline, IL) and thermostated at $50 \pm 0.5^{\circ} \mathrm{C}$ for $72 \mathrm{~h}$ under oxygen pressure of 200 psi using a procedure described elsewhere. ${ }^{19}$ PPMAP was separated from the reaction mixture by precipitating it with petroleum ether and purified by repeated precipitation followed by removal of the solvent by vacuum-drying. PPMAP was obtained as a white sticky material. The yield of PPMAP was found to be $16 \%$.

\section{RESULTS AND DISCUSSION}

\section{Molecular weight}

The number-average $\left(\bar{M}_{\mathrm{n}}\right)$ and weight-average $\left(\bar{M}_{w}\right)$ molecular weights of PPMAP were found to be 1743 and 2170, respectively. Generally, vinyl polyperoxides have a low molecular weight ${ }^{26}\left(\bar{M}_{n}=300-5000\right)$ because of various chain transfer reactions occurring during oxygen copolymerization. A detailed examination of the mechanism of formation revealed that this category of polymers undergo facile degradation during polymerization, generating chain transfer agents such as aldehydes, which react with macro growing radicals, resulting in a low molecular weight.

\section{${ }^{1} \mathrm{H}-\mathrm{NMR}$ spectra}

The ${ }^{1} \mathrm{H}-\mathrm{NMR}$ spectrum of PPMAP is given in Figure 1. The signals at $\delta 1.48,4.15$, and $6.4-7.4 \mathrm{ppm}$ are assigned to the methyl, methylene, and aromatic protons, respectively. The methyl signal is not shifted, whereas the methylene signal is shifted considerably downfield because of the two oxygen atoms directly attached to it. No homopolymer impurities can be detected from the NMR spectrum. All the groups present simple first-order spectra. The methyl and methylene protons constitute the $\mathrm{A}_{3}$ and $\mathrm{A}_{2}$ spin systems, respectively. As in the case of other vinyl polyperoxides, here, too, the molecular weight and the end groups are determined by chain transfer reactions. In PPMAP, as in poly(methyl methacrylate peroxide), ${ }^{27}$ the chain begins with $\mathrm{HO}_{2}$ $\mathrm{CH}_{2}-\mathrm{C}\left(\mathrm{CH}_{3}\right)\left(\mathrm{COOC}_{6} \mathrm{H}_{5}\right)=$ and $\mathrm{O}=\mathrm{CH}-\mathrm{O}-\mathrm{O}-\mathrm{C}\left(\mathrm{CH}_{3}\right)$ $\left(\mathrm{COOC}_{6} \mathrm{H}_{5}\right)$ - groups and terminates with $-\mathrm{CH}=\mathrm{C}\left(\mathrm{CH}_{3}\right)$ $\left(\mathrm{COOC}_{6} \mathrm{H}_{5}\right)$ groups. Thus, the major terminating group in PPMAP is the unsaturated chain end. This is clearly reflected in the ${ }^{1} \mathrm{H}-\mathrm{NMR}$ spectrum of PPMAP. The peak at $\delta$ $5.86 \mathrm{ppm}$ (doublet) corresponds to the $\mathrm{O}_{2}-\mathrm{CH}^{*}=\mathrm{C}$ $\left(\mathrm{CH}_{3}\right)\left(\mathrm{COOC}_{6} \mathrm{H}_{5}\right)$ proton and the peak at $\delta 9.8 \mathrm{ppm}$ to the $\mathrm{O}=\mathrm{CH}^{*}-\mathrm{O}-\mathrm{O}-\mathrm{C}\left(\mathrm{CH}_{3}\right)\left(\mathrm{COOC}_{6} \mathrm{H}_{5}\right)$ - proton.

\section{${ }^{13}$ C-NMR spectra}

The ${ }^{13} \mathrm{C}$-NMR spectrum (Fig. 2) exhibits signals corresponding to the four carbon atoms present in the repeat unit. The signals at $\delta 18.5,76.1$, and $82.9 \mathrm{ppm}$ are assigned to the methyl, methylene, and quaternary carbon atoms, respectively. The aromatic carbon atom bonded to oxygen gives a signal at $151.4 \mathrm{ppm}$, whereas the ortho, para, and meta carbons resonate at 121.7, 125.7, and 129.4 ppm, respectively. A considerable downfield shift of the methylene and the quaternary carbon results from the two electronegative oxygen atoms bonded to it. The peak at $166.6 \mathrm{ppm}$ is assigned to the carbonyl groups present in the repeating unit.

\section{FT-IR spectra}

The FT-IR spectrum of PPMAP is shown in Figure 3. The strong band near $1047 \mathrm{~cm}^{-1}$ is assigned to the peroxide $\left(-\mathrm{O}-\mathrm{O}-\right.$ ) bond stretching. The intense band at $1128 \mathrm{~cm}^{-1}$ results from the $\mathrm{C}-\mathrm{O}$ stretch. The bands appearing in the region, 2925-3030 $\mathrm{cm}^{-1}$ are assigned to the aliphatic and aromatic $\mathrm{C}-\mathrm{H}$ stretching modes. The broad absorption centered at $3500 \mathrm{~cm}^{-1}$ is attributed to the hydroxyl and hydroperoxide end groups. The formation of these end groups via various chain transfer mechanism is known. ${ }^{27}$ The very intense band appearing at $1744 \mathrm{~cm}^{-1}$ is assigned to the carbonyl groups present in the repeat unit. Other carbonyl groups present in the different end groups also show infrared absorption in this region, and hence they are not distinguishable. The weak absorption band at $1600 \mathrm{~cm}^{-1}$ is a result of the stretching of the $\mathrm{C}=\mathrm{C}$ group present in the terminating group. The major terminating group is

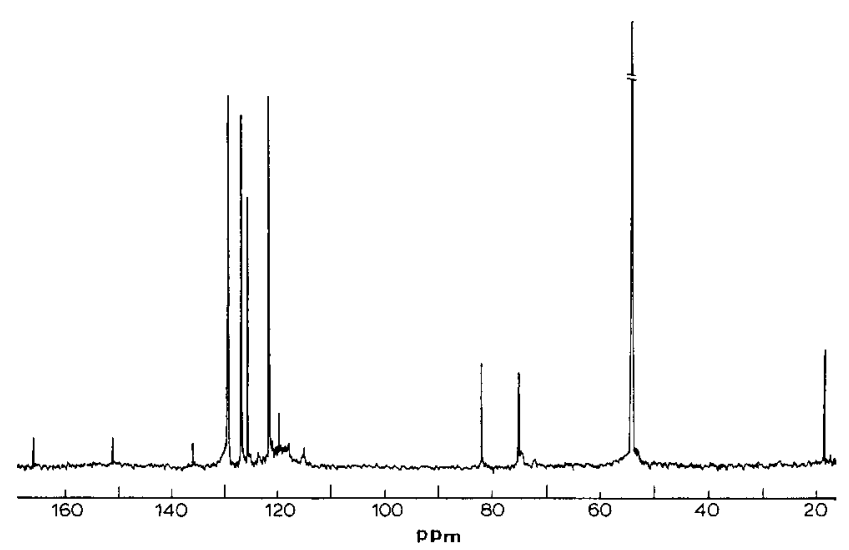

Figure $2{ }^{13} \mathrm{C}-\mathrm{NMR}$ spectrum of PPMAP in $\mathrm{CH}_{2} \mathrm{Cl}_{2}$. 


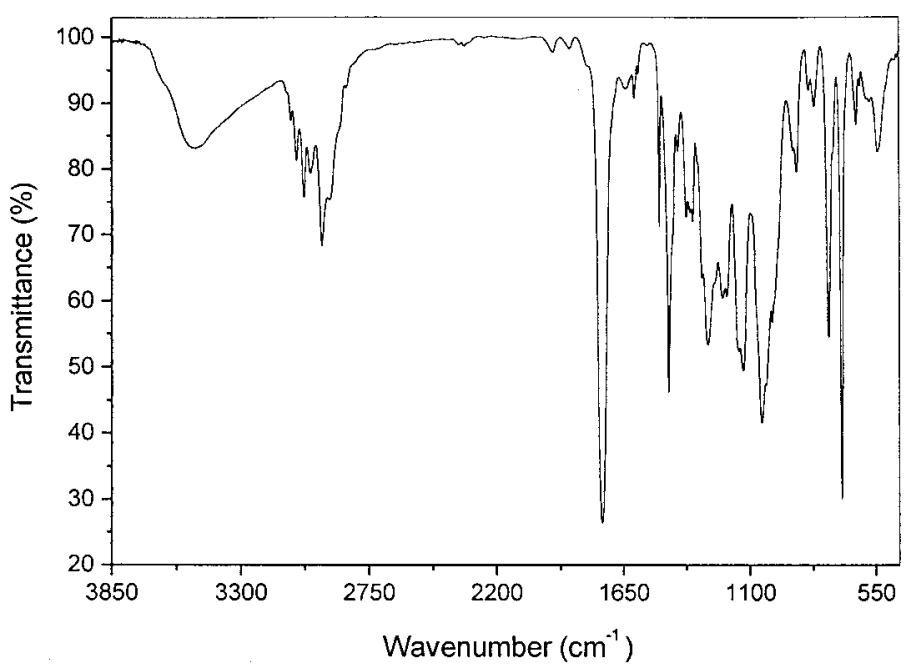

Figure 3 FT-IR spectra of PPMAP.

$-\mathrm{CH}=\mathrm{C}\left(\mathrm{CH}_{3}\right)\left(\mathrm{COOC}_{6} \mathrm{H}_{5}\right)$, as in poly $(\alpha$-methylstyrene peroxide). ${ }^{27,28}$

Based on the above discussion, the general structure of PPMAP can be given as<smiles>CCC(C)(CC)OOCCO</smiles>

\section{Thermal degradation}

The DSC studies were carried out at heating rates of $5^{\circ} \mathrm{C}$, $10^{\circ} \mathrm{C}, 20^{\circ} \mathrm{C}, 40^{\circ} \mathrm{C}$, and $80^{\circ} \mathrm{C} \mathrm{min}^{-1}$. A typical thermogram is given in Figure 4 . The studies reveal a highly exothermic degradation of PPMAP. The $\Delta H_{f}^{0}$ of the compounds studied here in their optimized structure are listed in Table I. The

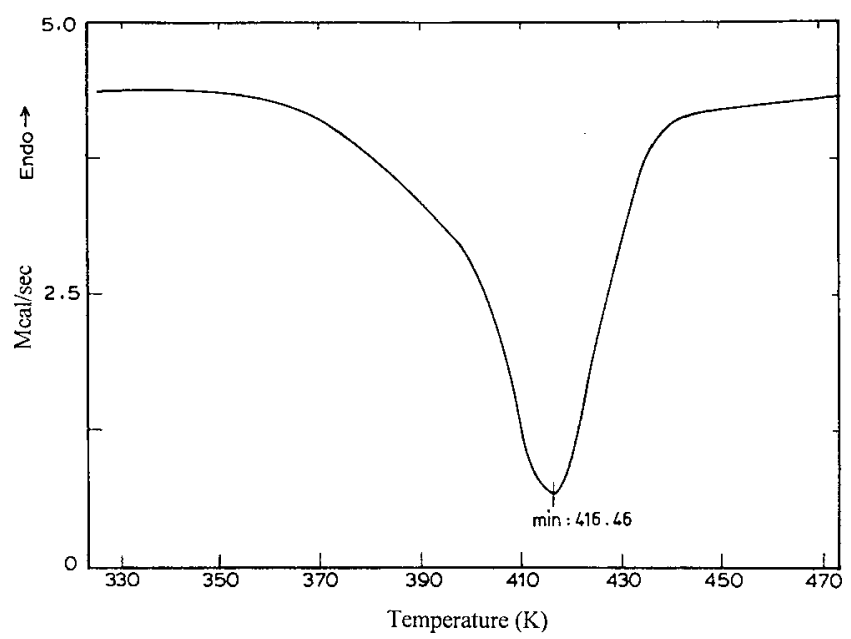

Figure 4 DSC thermogram of PPMAP at a heating rate of $10^{\circ} \mathrm{C} / \mathrm{min}$. enthalpy of degradation, $\Delta H_{d}{ }^{0}$ (the mean area under the exotherm at various heating rates), was calculated using the data given in Table I and was found to be $-48.6 \pm 2 \mathrm{kcal}$ $\mathrm{mol}^{-1}$, after applying a correction for the heat of vaporization $\left(\Delta H_{f}^{0}\right)$ of formaldehyde. The $\Delta H_{y}{ }^{0}$ for formaldehyde has been reported ${ }^{29}$ as $5.90 \mathrm{kcal} \mathrm{mol}^{-1}$. Because of the similarities between PPMAP and PSP in the heat of degradation, it is likely that PPMAP also shows auto-pyrolyzability and auto-combustibility, although no studies in this regard have been reported.

A Kissinger's plot ${ }^{30}$ of $\ln \phi / T_{m}{ }^{2}$ versus $1 / T_{m}$, where $\phi$ denotes the heating rate and $T_{m}$ the peak temperature in the DSC thermogram, is given in Figure 5. The slope of this straight-line plot yields the activation energy $\left(E_{d}\right)$ for the degradation process. The value of $E_{d}$ was found to be 39.44 $\pm 2 \mathrm{kcal} \mathrm{mol}^{-1}$, which is comparable to the dissociation energy of the $\mathrm{O}-\mathrm{O}$ bond (Table II). This, as well as the symmetrical nature of the DSC thermogram (Fig. 4), suggests that the degradation of PPMAP is a single-step process and is initiated by the scission of the $\mathrm{O}-\mathrm{O}$ bond. Thermogravimetric analysis (Fig. 6) of the polymer was carried out under a nitrogen atmosphere at a heating rate of $10^{\circ} \mathrm{C}$ $\min ^{-1}$. Weight loss occurred in a single step beginning at $90^{\circ} \mathrm{C}$ and ending at $150^{\circ} \mathrm{C}$, where the weight loss was almost complete.

From the results of the degradation product analysis ${ }^{22}$ and the measurement of $E_{d}$ for the degradation process (corresponding to the scission of the $\mathrm{O}-\mathrm{O}$ bond), a radical chain scission mechanism for the degradation of PPMAP, similar to that of PSP, could be proposed, ${ }^{9}$ as given below:

TABLE I

Thermochemical Data

\begin{tabular}{lll}
\hline \multirow{1}{*}{ Compound } & \multicolumn{2}{c}{$\Delta H_{f}^{0}\left(\mathrm{kcal} \mathrm{mol}^{-1}\right)$} \\
\cline { 2 - 3 } & Value & Reference \\
\hline PMA & -30.74 & this work \\
Phenyl pyruvate & -76.63 & this work \\
Formaldehyde $(\mathrm{g})$ & -27.7 & 29,33 \\
PPMAP & -44.14 & this work \\
\hline
\end{tabular}




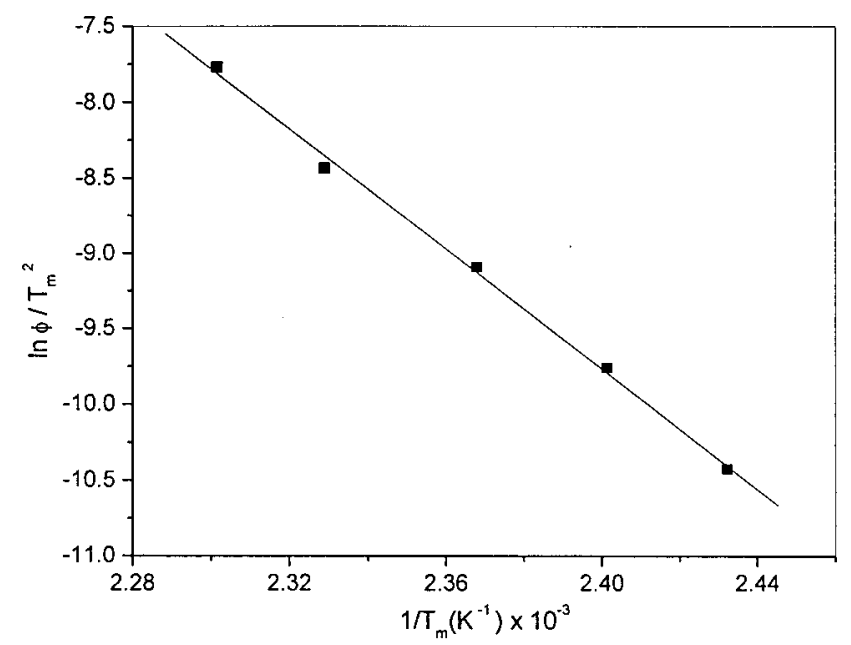

Figure 5 Kissinger's plot of $\ln \phi / T_{m}{ }^{2}$ against $1 / T_{m}$.

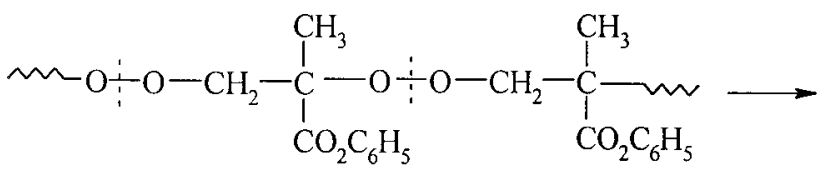<smiles>CC([O-])([O-])C(C)(C)COOOCCO</smiles><smiles>CCCCCCCOC(=O)C(C)(CO)C(=O)O</smiles>

$$
\mathrm{CH}_{2}=\mathrm{O}+\mathrm{H}_{3} \mathrm{C}-\stackrel{\mathrm{O}}{\mathrm{II}}-\mathrm{CO}_{2} \mathrm{C}_{6} \mathrm{H}_{5}
$$

The above mechanism indicates that the exotherm observed in the DSC is a result of the primary degradation of PPMAP. This finds support from the thermochemical calculations.

To calculate the heat of degradation $\left(\Delta H_{d}{ }^{0}\right)$ of PPMAP, its heat of formation $\left(\Delta H_{f}^{0}\right)$ is required. This was evaluated from the heat of polymerization $\left(\Delta H_{p}{ }^{0}\right)$.

The reaction of $\mathrm{O}_{2}$ with phenyl methacrylate leads to the formation of PPMAP,

$$
\begin{aligned}
\mathrm{n} \mathrm{CH}_{2} & =\mathrm{C}\left(\mathrm{CH}_{3}\right)\left(\mathrm{COOC}_{6} \mathrm{H}_{5}\right)+\mathrm{n} \mathrm{O}_{2} \\
& \rightarrow-\left[-\mathrm{O}-\mathrm{CH}_{2}-\mathrm{C}\left(\mathrm{CH}_{3}\right)\left(\mathrm{COOC}_{6} \mathrm{H}_{5}\right)-\mathrm{O}-\right]_{n}+\Delta H_{P}{ }^{0}
\end{aligned}
$$

In this process one $\mathrm{C}=\mathrm{C}$ bond and one $\mathrm{O}=\mathrm{O}$ bond are broken to form one $\mathrm{O}-\mathrm{O}$, one $\mathrm{C}-\mathrm{C}$, and two $\mathrm{C}-\mathrm{O}$ bonds. Using the bond energy data given in Table II, the value of

TABLE II

Bond Energy Data

\begin{tabular}{lcl}
\hline \multicolumn{1}{c}{ Bond type } & Bond energy $\left(\mathrm{kcal} \mathrm{mol}^{-1}\right)$ & Ref. \\
\hline $\mathrm{C}=\mathrm{C}$ & 145.8 & 34,35 \\
$\mathrm{C}-\mathrm{C}$ & 82.8 & 35 \\
$\mathrm{C}=\mathrm{O}$ formaldehyde & 166.0 & 34,35 \\
$\mathrm{C}=\mathrm{O}$ ketones & 179.0 & 34,35 \\
$\mathrm{C}-\mathrm{O}$ & 85.5 & 34,35 \\
$\mathrm{O}=\mathrm{O}$ & 119.1 & 34,35 \\
$\mathrm{O}-\mathrm{O}$ & 32.0 & 35 \\
\hline
\end{tabular}

$\Delta H_{P}{ }^{0}$ for PPMAP was calculated to be $20.9 \mathrm{kcal} \mathrm{mol}^{-1}$. However, $\Delta H_{P}{ }^{0}$ also depends on structural factors. For example, in vinyl polymerization the cleavage of one $\mathrm{C}=\mathrm{C}$ bond in the monomer gives rise to two $\mathrm{C}-\mathrm{C}$ bonds in the polymer, and the heat evolved in the process is $19.8 \mathrm{kcal}$ $\mathrm{mol}^{-1}$, compared with the experimental value $\Delta H_{P}{ }^{0}$ of 12.3 $\mathrm{kcal} \mathrm{mol}^{-1}$ for poly(phenyl methacrylate). ${ }^{31}$ Taking into account the structural factors, ${ }^{32}$ we therefore can take the

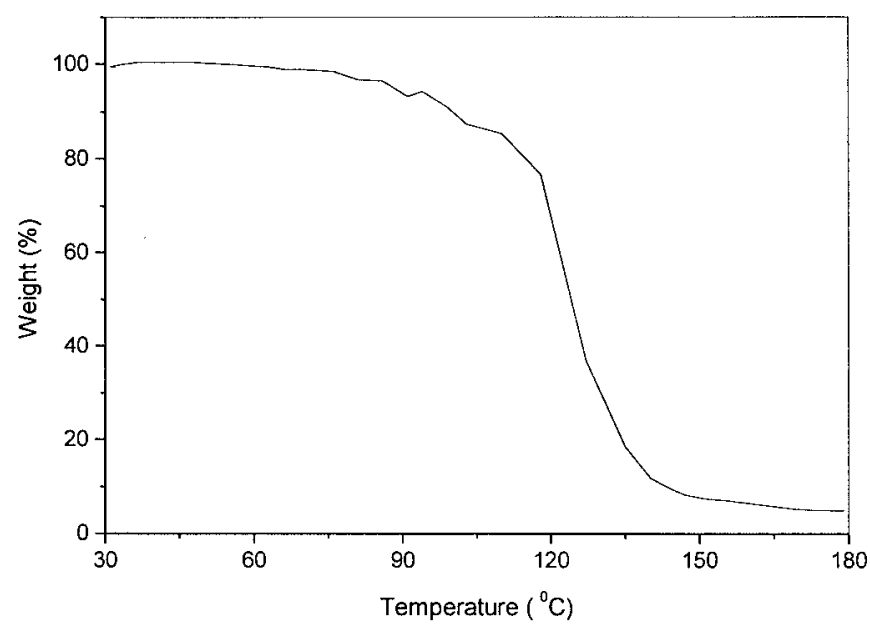

Figure 6 TGA curve of PPMAP at a heating rate of $10^{\circ} \mathrm{C} /$ min. 
actual value of $\Delta H_{P}{ }^{0}$ for PPMAP to be $13.4 \mathrm{kcal} \mathrm{mol}^{-1}$. Using this value and the $\Delta H_{f}^{0}$ for PMA (Table I), we obtain for PPMAP the $\Delta H_{f}^{0}$ as $-44.14 \mathrm{kcal} \mathrm{mol}^{-1}$.

The value of $\Delta H_{d}{ }^{0}$ for PPMAP was calculated by two different procedures.

1. Using $\Delta H_{f}^{0}$, from the degradation scheme the heat change during the degradation of PPMAP is obtained theoretically to give formaldehyde (vapor) and phenyl pyruvate.

$$
\begin{aligned}
\Delta H_{f}^{0}(\mathrm{PPMAP}) \rightarrow \Delta H_{f}^{0}\left(\mathrm{CH}_{3}-\mathrm{CO}-\mathrm{COOC}_{6} \mathrm{H}_{5}\right) \\
+\Delta H_{f}^{0}\left(\mathrm{CH}_{2} \mathrm{O}\right)+\Delta H_{d}{ }^{0}
\end{aligned}
$$

It was found to be $-54.29 \mathrm{kcal} \mathrm{mol}^{-1}$ after incorporating the correction for the heat of vaporization of formaldehyde.

2. The $\Delta H_{d}{ }^{0}$ was also calculated from the bond dissociation energies. During the process of degradation of PPMAP, one $\mathrm{C}-\mathrm{C}$ and one $\mathrm{O}-\mathrm{O}$ bonds are broken, while two $\mathrm{C}-\mathrm{O}$ bonds are converted to two $\mathrm{C}=\mathrm{O}$ bonds and formaldehyde is vaporized. The calculated enthalpy change $\left(\Delta H_{d}{ }^{0}\right)$ for this process is $-53.3 \mathrm{kcal}$ $\mathrm{mol}^{-1}$.

A mean value of $-53.8 \mathrm{kcal} \mathrm{mol}^{-1}$ was taken for $\Delta H_{d}{ }^{0}$ of PPMAP from the values of $\Delta H_{d}{ }^{0}$ obtained by the two methods $\left(-54.29\right.$ and $\left.-53.3 \mathrm{kcal} \mathrm{mol}^{-1}\right)$. The small difference between the experimental and theoretical values of $\Delta H_{d}{ }^{0}$ may arise from: (a) the approximation involved in the thermochemical input data, (b) the occurrence of minor side reactions during the degradation of PPMAP, and (c) the lower yields of aldehydes under the experimental conditions. The value of $\Delta H_{d}{ }^{0}$ of PPMAP suggests that the process should be exothermic. The good agreement between the experimentally measured and thermodynamically calculated values of $\Delta H_{d}{ }^{0}$ clearly demonstrates that the proposed mechanism of degradation should be acceptable.

\section{CONCLUSIONS}

The 1:1 copolymeric structure of PPMAP was confirmed spectroscopically for the first time. A radical chain-scission mechanism for the degradation of PPMAP has been proposed based on the analysis of its degradation products and kinetic studies by DSC. PPMAP shows a highly exothermic heat of degradation, and degradation is controlled by the dissociation of the peroxide $(-\mathrm{O}-\mathrm{O}-$ ) bond in the polymer backbone. The mechanism of the primary exothermic degradation has been substantiated by thermochemical calculations.

The authors sincerely thank Mr. S. Sundarrajan for recording the GPC. We gratefully thank the Central Power Research
Institute (CPRI, Bangalore, India) for providing the DSC facilities.

\section{References}

1. Mogilevich, M. M. Russian Chem Rev 1979, 48(2), 199.

2. Staudinger, H. Ber 1925, 58B, 1075.

3. Russel, G. A. J Am Chem Soc 1956, 78, 1035.

4. Handy, C. T.; Rothrock, H. S. J Am Chem Soc 1958, 80, 5306.

5. Mayo, F. R.; Miller, A. A.; Russell, G. A. J Am Chem Soc 1958, 80, 2500.

6. Gozzo, F.; Carraro, G. Nature 1965, 206, 507.

7. Bovey, F. A.; Kolthoff, I. M. J Am Chem Soc 1947, 69, 2143.

8. Miller, A. A.; Mayo, F. R. J Am Chem Soc 1956, 78, 1017.

9. Mayo, F. R.; Miller, A. A. J Am Chem Soc 1956, 78, 1023.

10. Mayo, F. R. J Am Chem Soc 1958, 80, 2465.

11. Van Sickle, D. E.; Mayo, F. R.; Arluck, R. M.; Syz, M. G. J Am Chem Soc 1967, 89, 67.

12. Mayo, F. R.; Castelman, J. K.; Mill, T.; Silverstein, R. M.; Rodin, O. J Org Chem 1974, 39, 889.

13. Kishore, K. J Chem Eng Data 1980, 25, 99.

14. Mayo, F. R.; Cais, R. E. Macromolecules 1981, 14, 885.

15. Kishore, K.; Mukundan, T. Nature 1986, 324, 130.

16. Murthy, K. S.; Kishore, K.; Krishna Mohan, V. Macromolecules 1994, 27, 7107.

17. Mukundan, T.; Bhanu, V. A.; Kishore, K. J Chem Soc, Chem Commun 1989, 12, 780.

18. Subramaniam, K.; Murthy, K. S.; Kishore, K. Polymer 1997, 38, 527.

19. Subramaniam, K.; Kishore, K. Eur Polym J 1997, 33, 1365.

20. Cais, R. E.; Bovey, F. A. Macromolecules 1977, 10, 169.

21. Jayaseharan, J. Ph.D. Dissertation, Indian Institute of Science, Bangalore, 1998.

22. Razuvaev, G. A.; Boguslavskaya, L. S.; Barabashina, R. A. Zhurnal Organicheskoi Khimii 1972, 8, 1601.

23. Insight II user guide, version 2.3.0. Biosym Technologies: San Diego, CA, 1993.

24. Dewar, M. J. S.; Zeobisch, E. G.; Healy, E. F.; Stewart, J. J. P. J Am Chem Soc 1985, 107, 3920.

25. Clark, T.; Chandrasekhar, J. Israel J Chem 1993, 33, 435.

26. Mukundan, T.; Kishore, K. Prog Polym Sci 1990, 15, 475.

27. Ganesh, K.; Paramasivam, S.; Kishore, K. Polym Bull 1996, 37, 785 .

28. Jayanthi, S.; Kishore, K. J Polym Mater 1998, 15, 5.

29. Weast, R. C. Eds. CRC Handbook of Chemistry and Physics, 59th ed.; CRC press: Cleveland, 1978.

30. Kissinger, H. E. Anal Chem 1957, 29, 1702.

31. Sawada, H. Thermodynamics of Polym; Marcel Dekker: New York, 1976; p 41.

32. Kishore, K.; Ravindran, K. Macromolecules 1982, 15, 1638.

33. Karapetyants, M. Kh.; Karapetyants, M. L. Thermodynamic Constants of Inorganic and Organic Compounds; translated by J. Schmorak; Ann Arbor-Humphrey Science: Ann Arbor, MI, London, 1970.

34. Roberts, J. D.; Caserio, M. C. Modern Organic Chemistry; Benjamin: New York, 1967.

35. Deem, J. A., Ed. Lange's Handbook of Chemistry, 11th ed.; McGraw-Hill: New York, 1973. 